\title{
Non-contact tonometry in the postoperative eye
}

\author{
STEPHEN A VERNON \\ From University Hospital, Nottingham
}

SUMmaRY The Keeler Pulsair non-contact tonometer was compared with the Goldmann applanation tonometer in a series of 48 eyes after operation. A correlation coefficient of $0.92(\mathrm{p}<0.001)$ was found between the two instruments, with the Pulsair having a statistically significant tendency to overread the Goldmann slightly in this situation. The Pulsair was, however, shown to be effective in the identification of postoperative ocular hypertension with a high degree of sensitivity and specificity and good patient compliance, while reducing the risk of cross infection.

Most surgeons routinely measure the intraocular pressure (IOP) after intraocular procedures to detect abnormally high or low pressures. Applanation tonometers (AT) indent a known area of the cornea, and when the correct indentation is observed the pressure resisting indentation equates to the force applied, resulting in an estimate of the intraocular pressure. ${ }^{1}$

The Goldmann AT has become the standard instrument used for this purpose and requires a slitlamp to obtain readings. The Perkins hand held AT operates on a similar principle, and both instruments require the instillation of a local anaesthetic/ fluorescein combination prior to contact with the globe.

Non-contact tonometers (NCT) use a puff of air to create an applanation event on the cornea, the changes in the characteristics of the corneal light reflex so produced being measured electronically. This is achieved in the Pulsair NCT by a quantification of the alteration in the corneal reflection which falls on to light sensitive diodes within the instrument. The instrument senses when correct alignment with the cornea has been made by the operator and automatically fires the test pulse, which is approximately half the pressure produced by conventional NCTs (manufacturer's data). A digital readout gives the IOP. No anaesthetics or dyes are required in NCT, and this has led to these instruments being widely accepted by optometrists for glaucoma screening.

In view of the potential advantages of the no-touch NCT method of IOP estimation in the postoperative

Correspondence to Mr S A Vernon, FRCS, Academic Unit of Ophthalmology, University Hospital, Nottingham NG7 2UH. patient a study was designed to compare the use of the Keeler Pulsair NCT with the Goldmann AT.

\section{Material and methods}

A series of 45 patients ( 48 eyes) under the care of five surgeons were recruited for the study. Each eye had undergone a single intraocular procedure within 24 hours of the IOP measurements being taken. The operations were as follows: 37 cataract extractions (34 with IOL), seven peripheral iridectomies, and four trabeculectomies. Forty-two patients had one eye operated upon and three had both. Each eye had four readings taken with the NCT, the mean of the four being used in the correlation statistics. All readings were taken by the same operator (SAV) with the patients seated. A test pulse was demonstrated on the patient's cheek prior to the intraocular pressure recordings (Keeler have recently incorporated this suggestion into the operator's manual for the Pulsair). Goldmann AT was then performed within five minutes of the last NCT recording by an experienced operator who was unaware of the NCT result.

After the tonometry the patients were asked to state which of the two methods they preferred.

\section{Results}

Fig. 1 indicates the correlation of individual NCT means with AT readings, the line on the scatter diagram being a regression line. The correlation coefficient (r) at 0.92 is statistically significant at the $\mathrm{p}<0.001$ level (Student's $t$ test). The regression analysis equation indicates the degree to which the NCT tends to overread the AT. Fig. 2 shows this in 


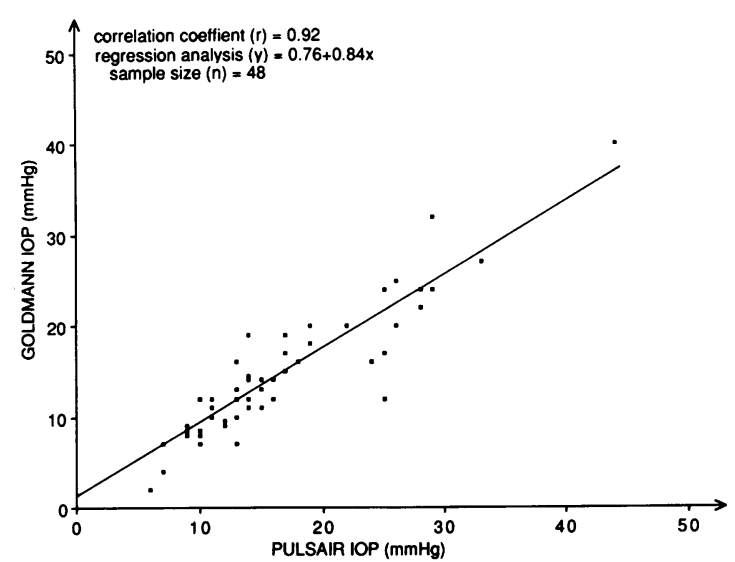

Fig. 1 Scatter diagram of applanation tonometer (Goldmann) IOP against mean non-contact tonometer (Pulsair) IOP.

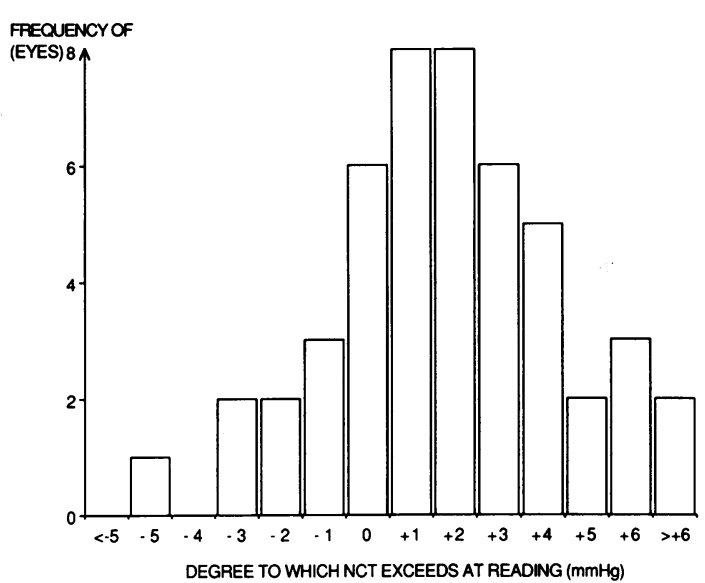

Fig. 2 Frequency histogram: Non-contact tonometer minus applanation tonometer in 48 eyes.

an alternative way by means of a frequency histogram. The NCT in postoperative cases has a statistically significant tendency to record a higher IOP than the AT $\left(0.01>p>0.001\right.$ by $\chi^{2}$ test $)$.

If the Goldman AT is accepted as the standard in tonometry, NCT sensitivity in screening for postoperative ocular hypertension can be defined as the number of true positive identified by the NCT (no of eyes in which AT and NCT read $>21 \mathrm{mmHg}$ ) divided by this number plus those falsely identified as negative by the NCT (eyes in which AT $>21 \mathrm{mmHg}$ and NCT $<22 \mathrm{mmHg}$ ). NCT specificity is defined as the total number of negatives correctly identified by the NCT (AT and NCT $<22 \mathrm{mmHg}$ ) divided by this number plus those falsely identified as positive by the NCT $(A T<22$ and NCT $>21 \mathrm{mmHg})$.
The NCT recorded 13 eyes with an IOP $>21$ $\mathrm{mmHg}(27 \%)$, whereas the AT recorded eight $(7 \%)$ over this level. All of the eyes which recorded $>21$ $\mathrm{mmHg}$ on the AT recorded $>21 \mathrm{mmHg}$ on the NCT ( $100 \%$ sensitivity). Five eyes recorded $>21 \mathrm{mmHg}$ on NCT when the AT reading was $<22 \mathrm{mmHg}(88 \%$ specificity), but in none of these did the NCT measure over $25 \mathrm{mmHg}$.

Ten of the 45 patients preferred the NCT, seven the AT, and 28 had no preference (no significant difference). It should be pointed out that all patients had had Goldmann AT at least once prior to surgery, whereas no patient had experienced the Pulsair NCT before the study. Although no record of the time taken to achieve the measurements was made, the four NCT readings usually took about 30 seconds to complete, and this was often considerably quicker than the AT.

\section{Discussion}

Most surgeons routinely measure the IOP after intraocular procedures to identify ocular hyper- or hypotension. An early postoperative rise in IOP commonly follows cataract surgery, ${ }^{2}$ and the IOP measures $>30 \mathrm{mmHg}$ at 22 hours after surgery in $8 \%$ of extracapsular procedures even without the use of viscoelastic materials. ${ }^{3}$

Viral diseases may be transferred by $\mathrm{AT},{ }^{4-6}$ and NCT avoids the ever increasing risk of cross infection by the AIDS virus, which is known to be present in the tears of infected individuals,? as no patient contact is necessary to perform the test.

The IOP measured with the Pulsair NCT has been designed to equate with the Goldmann AT over a range of 5 to $50 \mathrm{mmHg}$, with a correlation coefficient of 0.95 and a regression equation indicating a slight tendency to underread the Goldmann AT (manufacturer's data). These results were obtained with unoperated eyes.

It would appear from our study, the first to compare an NCT with an AT in the immediate postoperative period, that in this situation the Pulsair NCT has a statistically significant tendency to read higher than the Goldmann AT.

Postoperatively the IOP is often more difficult to measure accurately with the AT because of a number of factors. These include lid oedema, usually requiring manual elevation of the lid, increased tear film meniscus, and patient non-compliance. These factors may lead to an underestimation of the IOP by AT.

Momentary fluctuations in IOP result from changes in intraocular volume as a result of vascular pulsations associated with cardiac and respiratory cycles. ${ }^{8}$ The NCT samples these cycles, taking only milliseconds to record the IOP, and repeated read- 
ings do not reduce the recorded IOP. ${ }^{8}$ The steady state, however, is disturbed by the AT, which 'damps' the cycles. Repeated measurements reduce the IOP, ${ }^{9}$ and the reproducibility in non-operated eyes is to $\pm 2 \mathrm{mmHg}$ in only $65 \%$ of cases. ${ }^{10}$

The Pulsair measures the IOP only when the correct alignment has been made with the cornea as detected by light sensitive diodes receiving reflected light from the corneal surface, and, as no extraneous pressure is applied to the eye or adnexa, it measures the IOP at the moment the pulse is activated. With this and the high correlation coefficient in the nonoperated eye in mind, it may be that the NCT measures the IOP more accurately than the AT in postoperative cases.

Most surgeons would be unlikely to intervene in the immediate postoperative period unless the IOP rose above $25 \mathrm{mmHg}$, as most cases of ocular hypertension of this order of magnitude will resolve spontaneously within the next 24 hours with no sequelae. If the Pulsair NCT had been the only screening tonometer in this study, and only readings above $25 \mathrm{mmHg}$ on the NCT had been taken as significant, all eyes measuring $>21 \mathrm{mmHg}$ on the AT would have been identified and none would have been missed. AT could then have been used to confirm the NCT result, if indeed this was considered necessary, before intervention.

This study therefore suggests that the NCT, with its associated low cross infection risk, may be used to screen for postoperative ocular hypertension with high sensitivity and specificity and good patient compliance.
The author thanks the other consultants in the Ophthalmic Unit at the University Hospital, Nottingham, for the inclusion of patients under their care in this study, and also the junior staff who performed the applanation tonometry. The author has no financial interest in Keeler Ltd or the Pulsair NCT.

\section{References}

1 Moses RA. Intraocular pressure. In: Moses RA, Hart WM Jr, eds. Adler's physiology of the eye - clinical application. Missouri: Mosby, 1987: 240-1.

2 Rich W. Advantages and disadvantages of different methods of senile cataract surgery. Trans Ophthalmol Soc UK 1982; 102: 407-9.

3 Percival SPB. Sodium hyaluronate in cataract and intraocular surgery. Trans Ophthalmol Soc UK 1983; 103: 254-8.

4 D'Angelo LJ, Hierholzer JC, Holman S, Smith JD. Epidemic keratoconjunctivitis caused by adenovirus type 8 . Epidemiologic and laboratory aspects of a large outbreak. Am J Epidemiol 1981; 113: 44-9.

5 Buehler JW, Finton RJ, Goodman RA, et al. Epidemic keratoconjunctivitis: reports of an outbreak in an ophthalmology practice and recommendations for prevention. Infect Control $1984 ; 5: 390-4$

6 Barnard DL, Dean Hart JC, Marmion VJ, Clarke SKR. Outbreak in Bristol of conjunctivitis caused by adenovirus type 8, and its epidemiology and control. Br Med J 1973; ii: 165-9.

7 Fujikawa LS, Salahuddin SZ, Palestine AG, Masur H, Nussemblatt RT, Gallo RC. Isolation of human T-lymphotropic virus type III from the tears of a patient with acquired immunodeficiency syndrome. Lancet 1985 ; ii: 529-30.

8 Piltz JR, Starita R, Miron M, Henkind P. Momentary fluctuations in normal and glaucomatous eyes. Am J Ophthalmol 1985; 99: 333-9.

9 Wilke K. Effects of repeated tonometry: genuine and sham measurements. Acta Ophthalmol (Kbh) 1972; 50: 574-82.

10 Moses RA, Liu C-H. Repeated applanation tonometry. Am J Ophthalmol 1968; 66: 89-91.

Accepted for publication 27 April 1988. 